\title{
IMPACT OF BRICK KILNS' EMISSION ON SOIL QUALITY OF AGRICULTURE FIELDS IN THE VICINITY OF SELECTED BHAKTAPUR AREA
}

\author{
Gajendra Bhakta Suwal
}

Department of Electronics and Communication, Khwopa Engineering College, Libali-08, Bhaktapur, Nepal

\begin{abstract}
The study was conducted to evaluate the impact of brick kilns' on different physiochemical parameters of soils of agricultural field, located in the vicinity of Bhaktapur. The study was carried out by measuring the $\mathrm{pH}$ value and the micro nutrients of the soil. During the entire study period, the $\mathrm{pH}$ of soil near brick kiln was measured to be 5.5 and as distance increased the $\mathrm{pH}$ of soil was recorded up to 6.9 which mean the soil was acidic near the kiln and was neutral farther away. The findings revealed that the $\mathrm{pH}$ value was high and nutrient content were deficient in soil at $50 \mathrm{~m}$ while increasing gradually at distances of $100 \mathrm{~m}$ and $150 \mathrm{~m}$ it was found opposite of it. It signifies that the quality of soil increases proportionally to the distance from the brick kiln area. Similarly, the micro nutrients like organic matter are also increased with increasing distance.
\end{abstract}

Keywords: Brick kiln emission, impact, soil quality, nutrients

\section{Introduction}

Brick production is a very large and traditional industry in many parts of Nepal. But, the brick sector in Nepal is unorganized and haphazard. The mushrooming of such industries is due to rapid population growth and urbanization that enhance the needs of urban residents for food, energy, and shelter. Bhaktapur district is one of the main important economic as well as cultural centers of Kathmandu valley. The district occupies an area of about 119 sq. km. Similarly, it is situated at an altitude in between 1372 and $2166 \mathrm{~m}$. The total population of the Bhaktapur district according to census of 2011 is 303,027(CBS, 2011). Population living in Municipalities of Bhaktapur district is 168,152 that is $55 \%$ of total. Rest of the population $45 \%$ live in the village of Bhaktapur district. Among of the 16 villages the total population of the Duwakot village(recently lies in the Changunarayan Municipality) is 10,461 and the average household size of Bhaktapur is 4.15 while that of Duwakot is 4.5 which is smaller than national household size of 4.9 (NPCS, 2011).

*Corresponding author: Gajendra Bhakta Suwal

Department of Electronics \& Communication Engineering, Khwopa Engineering College, Libali-8, Bhaktapur, Nepal

Email:gazensuwal@gmail.com

(Received: Nov 10, 2017 Accepted: May 20, 2018)
Developments of modern technologies have been a key determinant to accelerate industrialization and urbanization in developing countries like Nepal. But in a quest of rapid economic growth, developments are considered key priorities, while protection of environment has not been given the same importance. Thus, a number of factories, sited haphazardly, have been established leading to deterioration of natural resources like soil, water, and air. As a result, environment pollution is tremendously increasing due to industrialization and mechanization that is serving to fulfill demands of population. Brick kilns are established randomly in order to fulfill the rapid growth of urbanization. Due to the settlement of brick kiln in fertile land, the farmland has been degrading frequently throughout the year (MOA, 2014). Land degradation is reduction of land quality. Productivity of soil declines when land becomes degraded. It declines unless steps are taken to restore that productivity and check further losses. The raw materials used for brick productions are soil clay or sediments from river, which are rich in fine particles.

Only a considerable number of studies are available in literature regarding the impact of brick kiln .In context of Nepal, few studies have been done to 
indicate that brick kilns are responsible for deteriorating the quality of soil; especially in the case of Bhaktapur in particular places. So, there was a need for more studies to firmly establish the linkages between land degradation and brick kiln's and its impact on soil quality of agriculture fields. So, this research was conducted in a field-based study to assess the impact of brick kilns in one particular village of Bhaktapur district. In Bhaktapur District Duwakot area is one of the popular places for brick kilns and it is also the place where brick kiln industry are haphazardly settled in fertile land. There are altogether 13 brick kilns which are in operation for more two decades.

\section{Methodology}

\subsection{Selection of Sampling Area}

Duwakot area was selected for this research because of its agricultural cropped farmlands is being used haphazardly by the brick kiln industry continuously since the last couple of decades. In this area, most of people who owned the land do the farming vegetable and crops for their day to day living. Cash crop farming is also one of the major occupations of farmers of this area as well. They produce the vegetables and crops along the side of brick kilns. The farmland's topsoil has been continuously used for the production of brick on which farmers produce their vegetables. So, in order to check and analyze the quality of soil, Duwakot area was selected for the study. Sample soil was collected in four directions East, West, North and South respectively in distance of $50 \mathrm{~m}, 100 \mathrm{~m}$ and $150 \mathrm{~m}$ respectively from the kilns. Figure 1 shows the satellite view of sampling site area.

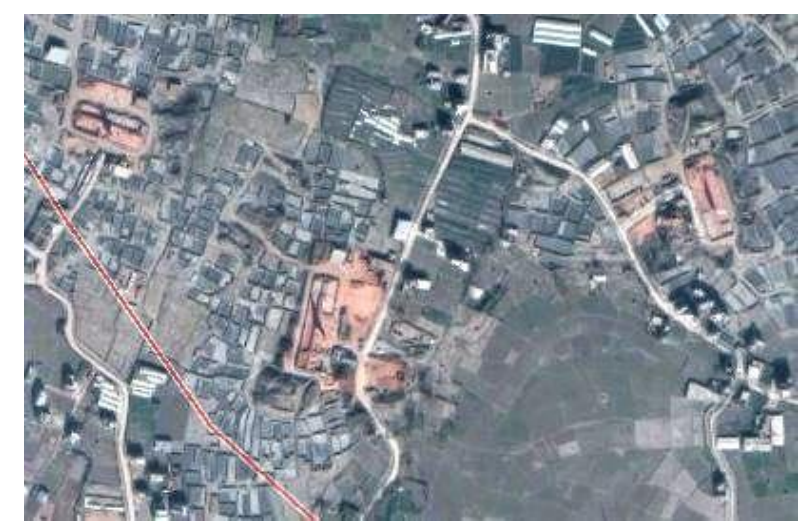

Fig 1 Satellite view of sampling site of Duwakot Brick Kiln Area

\subsection{Extraction of Soil Sample}

Soil samples were taken from $(15-30 \mathrm{~cm}$ depth) from around brick kiln chimney at distances of 50 $\mathrm{m}, 100 \mathrm{~m}$, and $150 \mathrm{~m}$ in (east, west, north, and south) direction. Each of the 14 samples collected from the site was transferred into sealed plastic bags and labeled appropriately. The soil samples were labeled as $R D$, where $R$ is distance from brick kiln $(R=50 \mathrm{~m}, 100 \mathrm{~m}$, and $150 \mathrm{~m})$ and $D$ is the direction ( $D=$ east, west, north, and south).The samples were air-dried after removal of external substances. A schematic block diagram of the soil sample collection procedure is shown in Figure 1 and Figure 2 shows the extraction of soil sample around the brick kiln area.

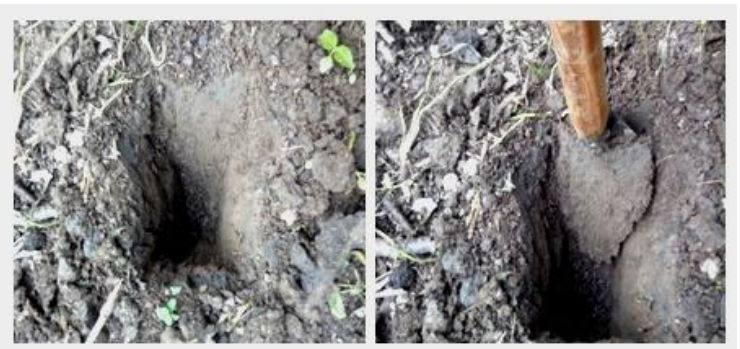

Fig 2 Soil Sample Extracting Around the Brick Kiln Area

\subsection{Determination of Physical \& Chemical Parameter of Soil Sample}

Physical and chemical analysis of the collected soil sample were done in five categories with which quality of soil or macronutrients of soil were obtained.. They are $\mathrm{pH}$, organic matter, nitrogen, phosphorous and potassium contained in the soil. For determination of $\mathrm{pH}, 10 \mathrm{gm}$ of soil was taken in $50 \mathrm{ml}$ beaker in $10 \mathrm{ml}$ distilled water and it was determined with the distilled water in a ratio (soil: water) of 1:2 electronically on a direct reading using the $\mathrm{pH}$ meter (Orion 5-star, Thermo); using a glass electrode with a saturated potassium chloride. Following Table 1 shows the $\mathrm{pH}$ range of the soil.

Similarly, Walkey-Black method applied to determine the organic matter concentration by taking $1 \mathrm{gm}$ of soil passing through $0.2 \mathrm{~mm}$ sieve. Afterwards $10 \mathrm{ml}$ of potassium dichromate $\left(\mathrm{K}_{2} \mathrm{Cr}_{2} \mathrm{O}_{7}\right)$ solution was mixed to it in $500 \mathrm{ml}$ conical flask. Likewise, Kjedhal Digestion method is implemented for determining the amount of Nitrogen in the soil in which $1 \mathrm{gm}$ of soil was taken in $50 \mathrm{ml}$ Kjeldhal digestion flask and $2 \mathrm{gm}$ catalyst 
digestion mixture was added with $10 \mathrm{ml}$ concentration of Suphuric acid.

Table 1 Classification of $\mathrm{pH}$ Range

\begin{tabular}{|c|c|c|}
\hline S.N & pH & Remarks \\
\hline 1. & $<4.5$ & Very Acidic(VA) \\
\hline 2 & From 4.5 to 5.5 & Acidic(A) \\
\hline 3. & From 5.5 to 6.5 & Soft Acidic(SA) \\
\hline 4. & From 6.5 to 7.5 & Neutral(N) \\
\hline 5. & Above $>7.5$ & Base(B)/Alkaline \\
\hline
\end{tabular}

(Source: From Ministry of Agriculture (MoA), Agriculture Department)

For phosphorous, taking $2.5 \mathrm{gm}$ of soil sample (i.e air dried $<2 \mathrm{~mm}$ ) the Oslen's Bicarbonate method was used. The method called Flame Photometer is implemented for determining the potassium macronutrient concentration for which $2 \mathrm{gm}$ of air dried soil was taken for this experiment. Table no. 1 shows the different standard scaling of $\mathrm{pH}$ value for different condition. It is the standardized classification of the $\mathrm{pH}$ values of the soil. This table shows the different category of $\mathrm{pH}$.

Table 2 pH Character of Soil Samples (* res=residence) level of the soil from very acidic to alkaline. Similarly, Table no. 3 indicates the classification of the different micro nutrients that is necessary for the proper growth of the plants. It is the tabulation of different nutrients like organic matter, nitrogen, phosphorous and potassium.

\section{Data Analysis Tool}

The brick kiln industry impact on the soil fertility analysis was done by using excel and SPSS tool. To generate the overall charts and the processing of raw data were performed in this software. Similarly, for the descriptive analysis of data and documentation was done through this software.

\subsection{Data Analysis}

For analyzing the data that are recorded through the field experiment is tabulated in Table 2 and in Table 4. In Table 2 it explained about the nature of the soil that was recorded around the brick kiln. i.e. it showed the $\mathrm{pH}$ concentration in different distances from the brick kiln location. Likewise, in Table 4 it showed the the concentration of the organic matter and other chemical concentration like nitrogen, phosphorous, potassium respectively.

\begin{tabular}{|c|c|c|c|}
\hline \multirow{2}{*}{$\begin{array}{c}\text { Direction with respect } \\
\text { to Brick Kiln }\end{array}$} & \multicolumn{2}{|c|}{ Distance from the Brick Kiln(meter) } \\
\cline { 2 - 4 } & $50 \mathrm{~m}$ & $100 \mathrm{~m}$ & $150 \mathrm{~m}$ \\
\hline East & $5.5(\mathrm{~A})$ & $6.0(\mathrm{~N})$ & $6.9(\mathrm{NN})$ \\
\hline West & $6.3(\mathrm{SA})$ & $* \operatorname{Res}$ & $*$ Res \\
\hline North & $5.7(\mathrm{SA})$ & $6.1(\mathrm{SA})$ & $6.5(\mathrm{SA})$ \\
\hline South & $6.5(\mathrm{SA})$ & $6.2(\mathrm{SA})$ & $6.9(\mathrm{NN})$ \\
\hline
\end{tabular}

Table 3 Classification of micro nutrients

\begin{tabular}{|c|c|c|c|c|c|}
\hline S.N & $\begin{array}{c}\text { Organic } \\
\text { Matter(\%) }\end{array}$ & $\begin{array}{c}\text { Nitrogen } \\
(\mathbf{N})(\boldsymbol{\%})\end{array}$ & $\begin{array}{c}\text { Phosphorous(P) } \\
\text { kg/hectare }\end{array}$ & $\begin{array}{c}\text { Potassium(K) } \\
\text { kg/hectare }\end{array}$ & Remarks \\
\hline 1. & $<1.25$ & $<0.05$ & $<15$ & $<55$ & Very Low(L) \\
\hline 2. & 1.25 to 2.5 & 0.05 to 0.1 & 10 to 31 & 55 to 110 & Low(L) \\
\hline 3. & 2.5 to 5.0 & 0.1 to 0.2 & 31 to 55 & 110 to 280 & Medium(M) \\
\hline 4. & 5 to 10 & 0.2 to 0.3 & 55 to 110 & $>$ High(H) \\
\hline 5. & $>10$ & $>03$ & $>110$ & $>500$ & Very High(VH) \\
\hline
\end{tabular}

(Source: From Ministry of Agriculture (MOA), Agricultural Department) 


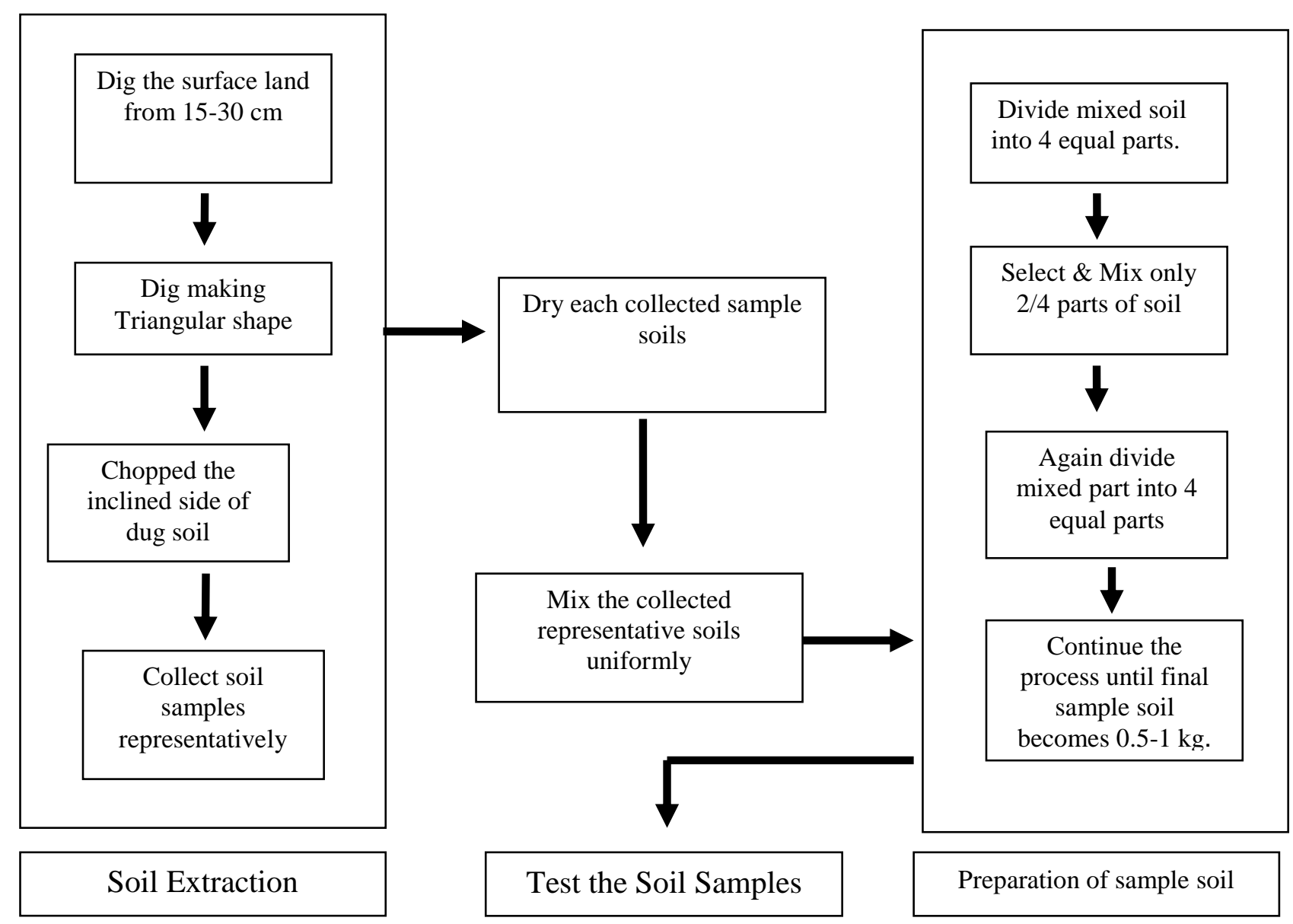

Fig 3 Block diagram of soil sample extraction method

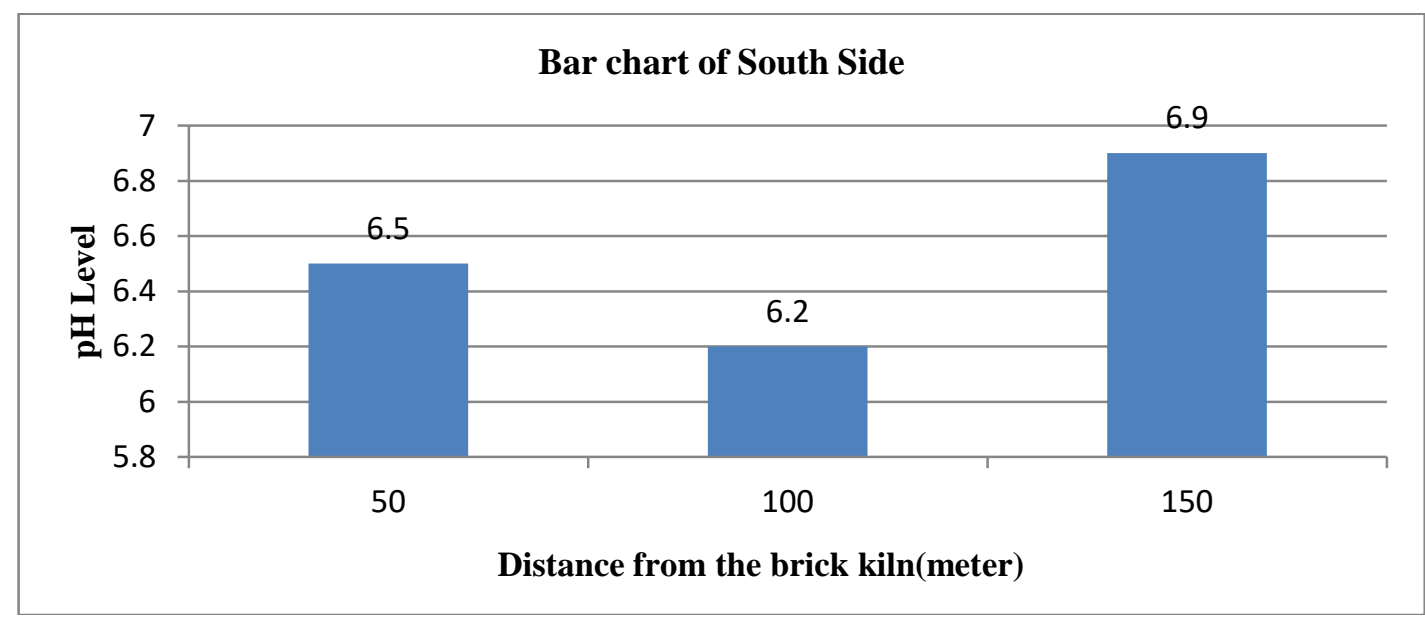

Fig $4 \mathrm{pH}$ of soil in south direction soil 


\section{Result and Discussion}

\subsection{Brick Kiln Impact Survey and Data Analysis}

a) pH Impact on soil

Soil $\mathrm{pH}$ is an important index of ecological condition of terrestrial environment. It affects the availability of nutrients to plants and the activity of soil microorganisms. $\mathrm{pH}$ provides a good identification of soil chemical nature where higher $\mathrm{pH}$ indicated optimal range for plant growth but lower $\mathrm{pH}$ causes problems for normal growth of the plants . The $\mathrm{pH}$ values of the samples ranged from 5.5 to 6.9 i.e. in Table no.. 3 was the overall measured $\mathrm{pH}$ values at different distance and direction respectively. Recorded $\mathrm{pH}$ of soil samples is acidic, slightly acidic and to neutral. So, the research shows that the $\mathrm{pH}$ of soil samples are acidic and soft acidic in nature at 50 $\mathrm{m}$ east and north is $5.5 \& 5.7$ respectively, so it clearly refers impact from brick kiln.

Similarly, the southern and eastern soil sample at 150 $\mathrm{m}$ and at eastern $100 \mathrm{~m}$ is neutral. The $\mathrm{pH}$ of soil at $100 \mathrm{~m}$ north, south is 6.1 and 6.2 , that the soil character is soft acidic thus these all findings revealed that as distance increases from the brick kiln then the soil quality is also increases. And the simultaneous respective bar chart diagram of $\mathrm{pH}$ of soil with respect distance and direction of brick kiln are shown in Figure 4, 5 and 6. As shown if figure the nature of the soil and its $\mathrm{pH}$ level was measured or found to be in decreasing manner. The bar chart diagram revealed that the soil near or around the brick kiln surrounding were found more acidic in nature, i.e. around $50 \mathrm{~m}$ in distance from the brick kiln the $\mathrm{pH}$ value in northern side and in the eastern side is measured to be 5.7 and 5.5 , which means the soil at that distance is soft acidic.

Likewise, in $100 \mathrm{~m}$ distance of eastern and northern side $\mathrm{pH}$ level was measure 6 and 6.1 respectively. Here, it showed that the $\mathrm{pH}$ level or concentration of acidic quantity is decreasing gradually. It showed that again the nature of soil at this distance is soft acidic.

Similarly, in $150 \mathrm{~m}$ distance from the brick kiln location the $\mathrm{pH}$ level was measured in eastern and northern side were 6.9 and 6.5. Here this $\mathrm{pH}$ level showed that as we move further from the brick kiln the value of $\mathrm{pH}$ concentration was measured comparatively low. Concentration of acid in soil was found low and more towards neutral.

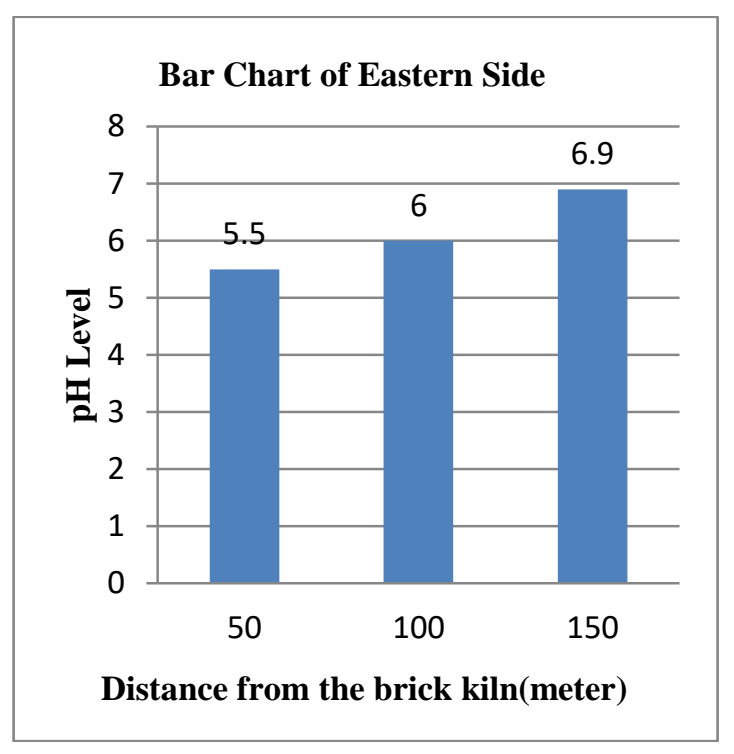

Fig $5 \mathrm{pH}$ of soil in east direction

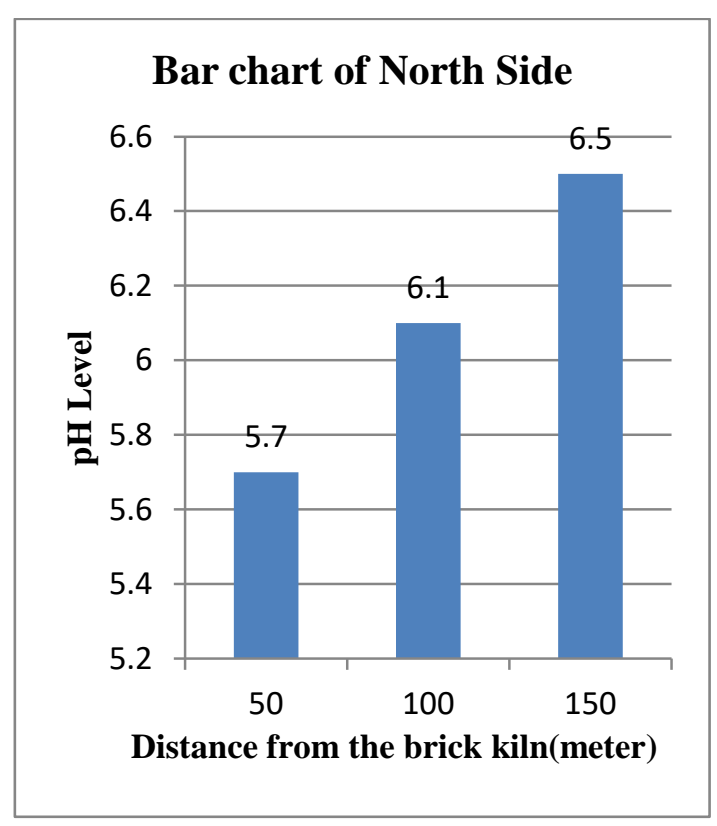

Fig $6 \mathrm{pH}$ of soil in north direction 
Table 4 Effect of brick kiln on macro nutrients concentration in soil at different distances

\begin{tabular}{|c|c|c|c|c|c|}
\hline \multirow{2}{*}{ Direction } & \multirow{2}{*}{$\begin{array}{l}\text { Distance } \\
\text { from the } \\
\text { brick } \\
\text { kiln(m) }\end{array}$} & \multicolumn{4}{|c|}{ Macro Nutrient Concentration } \\
\hline & & $\begin{array}{c}\text { Organic } \\
\text { Matter (\%) }\end{array}$ & $\begin{array}{c}\text { Nitrogen } \\
(\%)\end{array}$ & Phosphorous(kg/ha) & Potassium(kg/ha) \\
\hline \multirow{3}{*}{ East } & 50 & 2.74(M) & $0.14(\mathrm{M})$ & $306.9(\mathrm{VH})$ & $151.4(\mathrm{M})$ \\
\hline & 100 & $2.53(\mathrm{M})$ & $0.13(\mathrm{M})$ & $183.2(\mathrm{VH})$ & $242.8(\mathrm{M})$ \\
\hline & 150 & $2.83(\mathrm{M})$ & $0.14(\mathrm{M})$ & $224.4(\mathrm{VH})$ & $208.5(\mathrm{H})$ \\
\hline \multirow{3}{*}{ West } & 50 & 3.32(M) & $0.17(\mathrm{M})$ & 279.4(VH) & $288.5(\mathrm{M})$ \\
\hline & 100 & Res & Res & Res & Res \\
\hline & 150 & Res & Res & Res & Res \\
\hline \multirow{3}{*}{ North. } & 50 & $3.17(\mathrm{M})$ & $0.16(\mathrm{M})$ & $251.9(\mathrm{VH})$ & $174.2(\mathrm{M})$ \\
\hline & 100 & $1.91(\mathrm{~L})$ & $0.1(\mathrm{~L})$ & $178.6(\mathrm{VH})$ & 259.9(M) \\
\hline & 150 & $2.56(\mathrm{M})$ & $0.13(\mathrm{M})$ & 206.1(VH) & $305.6(\mathrm{H})$ \\
\hline \multirow{3}{*}{ South } & 50 & $2.65(\mathrm{M})$ & $0.13(\mathrm{M})$ & $210.7(\mathrm{VH})$ & $294.2(\mathrm{H})$ \\
\hline & 100 & $3.29(\mathrm{M})$ & $0.16(\mathrm{M})$ & $242.7(\mathrm{VH})$ & $442.7(\mathrm{H})$ \\
\hline & 150 & 2.99(M) & $0.15(\mathrm{M})$ & 206.1(VH) & 219.9(M) \\
\hline
\end{tabular}

b) Impact on micro nutrients concentration of soil

In case of micro nutrients, according to organic matter values ranges from $1.91 \%$ and $3.32 \%$ (Table 4) in compare to Table no. 2, the organic matter near to the brick kiln was found low due to low organic carbon content. The organic matter content in soil gradually increased with distance away from the kiln; however, the percentage of organic matter was recorded $3.32 \%$ at $50 \mathrm{~m}$ distance from the brick kiln. But in this west direction at $100 \mathrm{~m}$ and $150 \mathrm{~m}$ distance they are assumed to be zero because in this distance it is occupied by the residential area. In case of consumption of nutrients concentration, from Table 4 it can be concluded that the organic matter is almost moderate in all direction i.e. above of $2.5 \%$ except in $100 \mathrm{~m}$ distance of north is low organic i.e. $1.91 \%$. Here, the respective graphical representation of (Table 4) is shown in Figure 7, 8, 9 and 10. Likewise Figure 7, 8, 9 and 10 are the graphical representation of remaining macronutrients concentration of nitrogen phosphorous and potassium around the brick kiln area.

From Fig. 8, the nitrogen concentration in all direction of brick kiln is found medium. That is the concentration of Nitrogen is from least $0.1 \mathrm{~kg} / \mathrm{ha}$ to $0.17 \mathrm{~kg} / \mathrm{ha}$ which means the consumption of nitrogen is moderate. Similarly, regarding the nutrient concentration, the phosphorous (P) concentration is very high (Figure 9). Phosphorous to be normal or medium the phosphorous range should be from 31 to $55 \mathrm{~kg} / \mathrm{ha}$ (Table 3.7) but here the concentration of phosphorous is least from 178.6 to 306.9 which too high than the required one. Likewise, from Figure 10, the concentration of potassium is medium for all direction except in $50 \mathrm{~m}$ in west, $150 \mathrm{~m}$ in north and $100 \mathrm{~m}$ in south are high. 


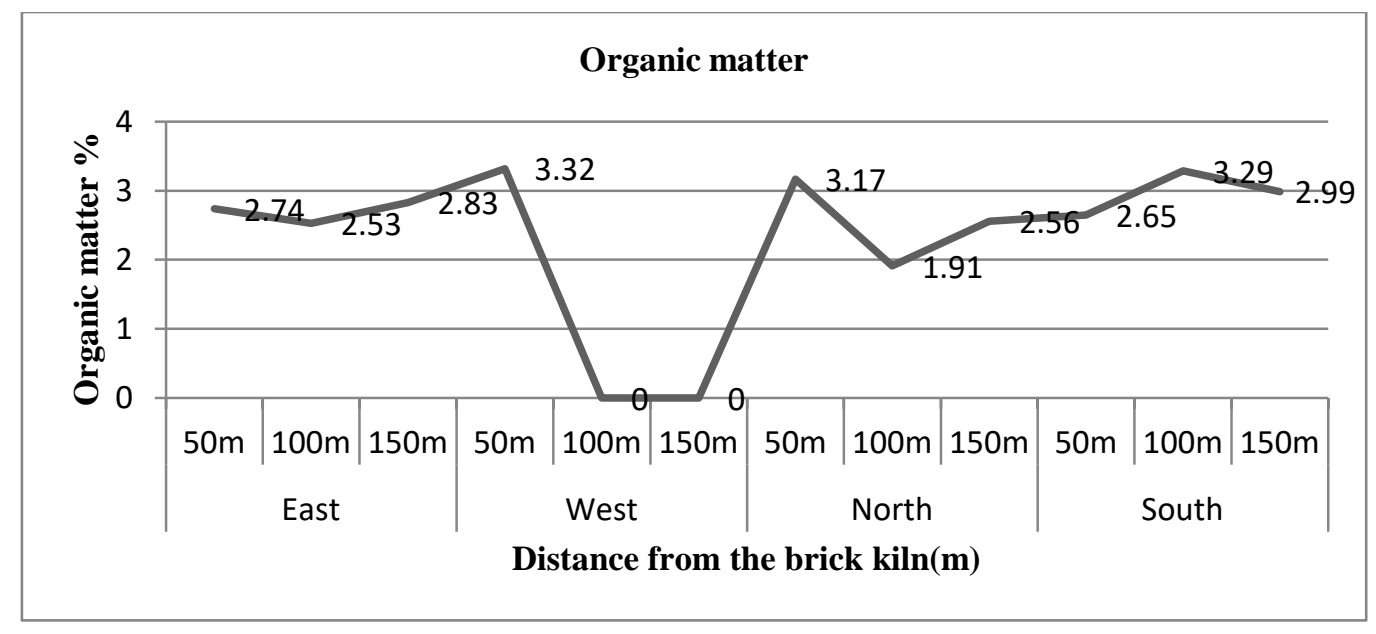

Fig 7 Organic matter nutrient concentration in soil

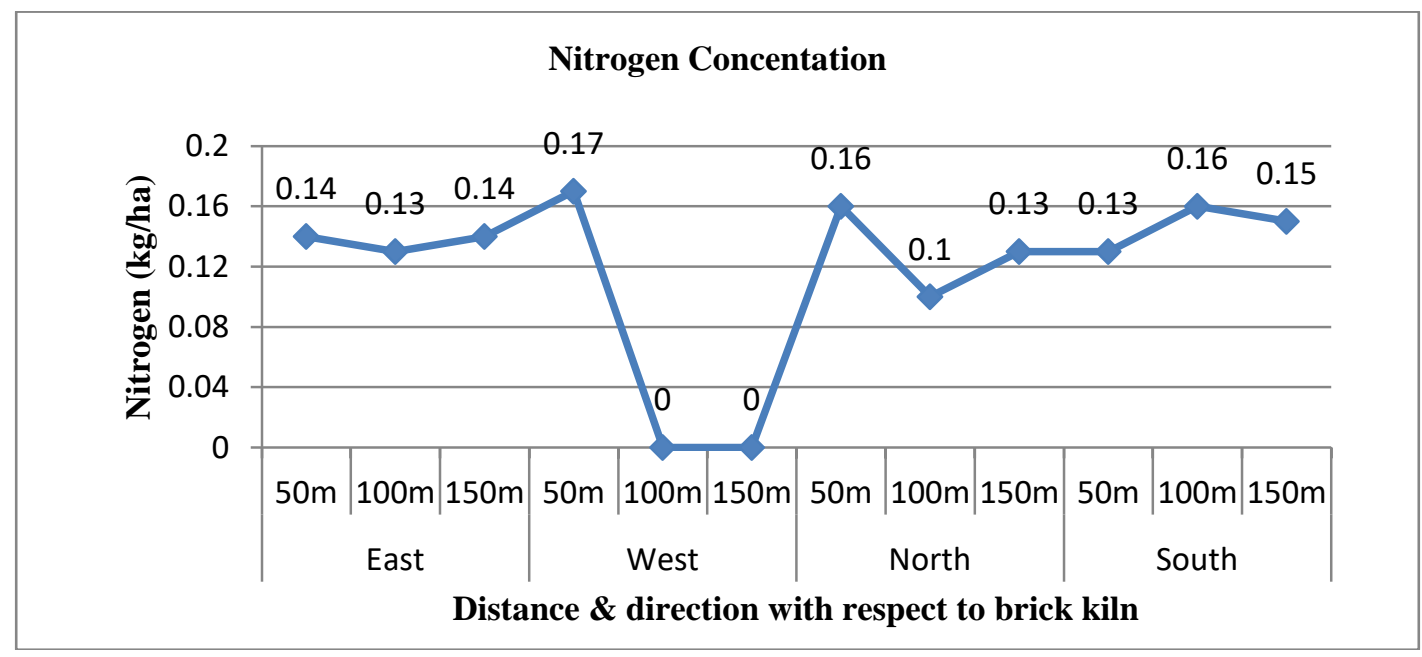

Fig 8 Nitrogen nutrient Concentration in soil

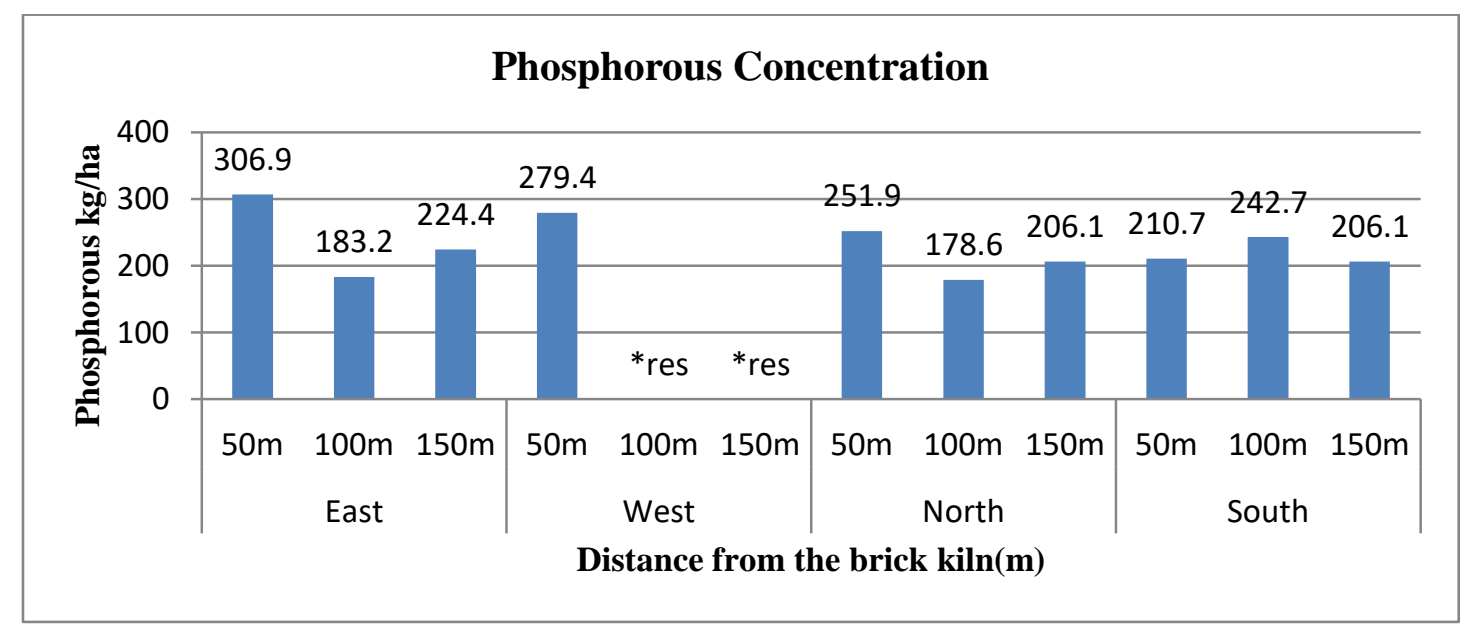

Fig 9 Phosphorous nutrient concentration of soil 


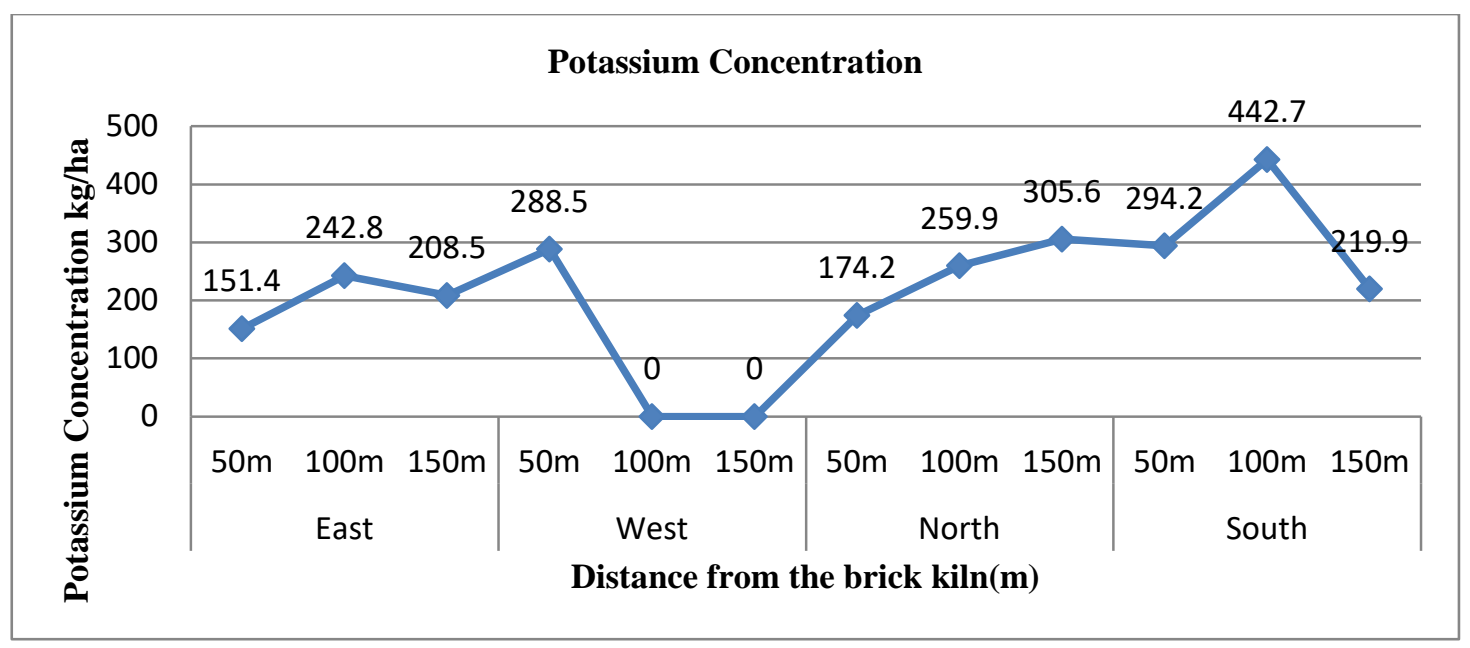

Fig 10 Potassium nutrients concentration in soil

\section{Conclusion}

After the analysis of soil samples taken from different distances from the brick kiln area, a general conclusion that could be reached is that the $\mathrm{pH}$ was found acidic near the brick kiln but as distance increases from brick kiln, the soil quality is increasing steadily but slowly. The least $\mathrm{pH}$ of soil near brick kiln was measured 5.5 and at most $\mathrm{pH}$ of soil was 6.9 which indicate that the $\mathrm{pH}$ of soil was acidic near the kiln and neutral farther away. Similarly, the organic matter content also increased along with increasing distance. The available nitrogen, phosphorous and potassium in soil samples examined had similar impact with increasing distance away from kiln's chimney. From the findings it revealed that the acidic soil was increased by $2 \%$, but neutral soil was decreased by $42 \%$ and soft acidic soil was increased by $40 \%$ which mean in overall soil is degrading tremendously due to brick kiln. Therefore, although the range of physical and chemical parameters of soil is within the permissible limit, their concentration is not uniform and rather varies with distance. This indicates deterioration of soil quality, so it is not found to be environmentally safe for agriculture.

\section{References}

[1] "Agriculture Soil Fertility Annual Report-2013 of Tehrathum", Palpa, Gulmi, Lele, Chitwan, Nepal
[2] Avita Corral Yadira., 1995, "Impact of Brick Kiln on Soil Fertility in Chihuahua", Chihuahua State, Mexico

[3] Bajaj J. C., Ghosh A. B, 1983, Hassan .R., and Singh. D., Laboratory Manual for Soil and Water Testing 1st Edition, Soil Testing Laboratory, Division of Soil Science and Agricultural Chemistry, IARI,New delhi, India

[4] Bell .M. L. and Gurung.A "Thestate of scientific evidence on air pollution and human health in Nepal," Environmental Research

[5] CBS, 2011, "National census 2068", Central Bureau of Statistics, Government of Nepal, Thapathali, Kathmandu.

[6] Das. R. "Causes and consequences of land degradation in and around the brick kilns of khejuri CD blocks over Coastal Medinipur in West Bengal", International Journal of Innovative Research and Development, vol. 4, no. 2, 2015

[7] MoA, 2013, "Soil Map Survey FY 2012-2013", Ministry of Agriculture, Government of Nepal.

[8] MoA, 2014, "Soil Map Survey FY 2013-2014", Ministry of Agriculture, Government of Nepal.

[9] NPCS, 2010/11, "Nepal living standards survey Statistical report volume one", Central Bureau Of Statistics, National Planning Commission Secretariat, Government of Nepal.

[10] Pradhan S.B, 1996. NARC "Soil and Plant Analysis Manual, The agro-enterprise and technology system project chemonics/ USAID/ HMG", 
[11] Sahir M.H., 2007, "Contamination of Heavy metal in Agricultural Field for Pakistan", Ph. D. thesis, University of engineering \& technology, Taxila Pakistan

[12] Soil Map of Phyuthan 2012, "Regional "Causes and consequences of land degradation in and around the brick kilns of khejuri CD blocks over Coastal Medinipur in West Bengal," International Journal of Innovative Research and Development, vol. 4, no. 2, 2015, Soil Management" ,Agricultural Department of Phyuthan, Nepal

[13] Tuan N.A., and Lefevre, T., 1996, "Analysis and Impact of Brick in Environment of Vietnam", Air Policy, Vol.24, No.12, pp.1089-1099.

[14] Zhang .X., Liu .F. Li, T., "Effect of brick kiln's emissions on Heavy metal (CD and CR) content of Contiguous soil and Plants", Hangzhou, China 